\title{
Exploration Of Accounting Software Usage: An Empirical Research Applied On The Pennsylvania Home Building Industry
}

Mark D. Law, Bloomsburg University, USA

Nancy Coulmas, Bloomsburg University, USA

\begin{abstract}
The purpose of this study was to investigate the utilization of information technology in accounting functions, related to the scale of operations, by Pennsylvania's home building contractors. The researchers examined whether differences in firm size played a factor in how often accounting or project management software was used for job costing, whether or not the primary accounting function was computerized, and if computerized, the primary program used for the accounting functions by home builders. According to the findings, the researchers concluded that there are significant differences among and between firm sizes in the use of accounting and project management software for job costing by Pennsylvania home building firms. Secondly, the data showed significant differences existed among firm sizes between the use of a computerized accounting system or manual accounting system. Finally, the data revealed that there are significant differences among firm sizes in the primary program used for estimating when a firm is computerized.
\end{abstract}

Keywords: Accounting, Accounting Software, Construction, Construction Technology.

\section{INTRODUCTION}

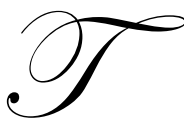

he structure and nature of the construction industry is different than most other sectors of the economy, such as the manufacturing industry. The construction industry is centered on a projectoriented approach in which most projects are unique and different. This project-oriented approach is in sharp contrast to the manufacturing industry, which is centered on a process-oriented approach in which the same item is mass produced under similar conditions (Ramos, 2002). In the construction industry, a project is a job or venture undertaken. The project entails the flow of information from the client's input through to the output in the form of the physical structure. The progression of the loop is repeated until the structure is completed. As such, the construction project is seen as a unique and complete job involving many interrelated tasks and often a very difficult practice to manage (Al-Jibouri \& Mawdesley, 2002).

The residential building arena could benefit from using accounting technology more efficiently in order to manage construction projects to stay on time and budget and increase profitability ("Partnership for", 2001). In order to keep the project on time and budget, financial information, in the form of reports, is vital and must be prepared on time and be reliable. This is where an efficient accounting system can be a valuable asset to a construction firm.

\section{LITERATURE REVIEW}

The construction industry is associated with a high degree of risk due to the project-oriented approach and the time-consuming nature of the industry. This, in turn, connects in principal to complicated business processes and activities (Kartam \& Kartam, 2001). In order to account for this risk, construction firms require additional accounting methods and techniques composed in the job cost system to track activities and progress on their jobs. 
Jobs are essentially projects, often associated with unique characteristics, which are completed to meet the specific needs of their clients. Job cost systems provide valuable information for the contractor and serve as the control center for the construction firm. To assist in the information delivery, projects are usually broken down into several distinct tasks and are spread out over a period or course of time. All projects have costs or expenditures associated with them. Cost generally include materials, labor, equipment, subcontractors, and allocated overhead. These costs are typically broken down and categorized into cost codes for improved analysis. There are two types of costs accounted for in a job cost system: estimated and actual costs. Estimated costs are the predictive costs of the project where as actual costs are the definitive cost incurred for the job. Most importantly, a job cost system compares the cost estimates to actual expenses on a job-to-job basis (User's guide, 2002).

A job cost system conveys further benefits beyond tracking materials, labor, equipment, subcontractors, and allocated overhead and their associated costs. Two additional benefits derived from the implementation of a job cost system are predictability and costs comprehension. A job cost system can help predict the outcome of a project and narrow the gray area as the project proceeds. By monitoring the estimate-actual variances, unpredicted variations can be uncovered and steps taken to amend these variations. This will help avoid unpleasant surprises on the overall costs and profitability on the projects. A good job cost system can also help the contractor understand the costs associated with a particular project. By understanding the costs in detail and in aggregate, this cost information can be used to assess efficiencies of the job and operations and be integrated into the management process. The cost information can also be applied to future projects to help prevent errors and omission (Wiersema, 1996). According to Forehand (2002), "the contractor should have a reliable job cost system in place to record contract costs accurately" (p. 18).

The purpose of accounting is to provide accurate and useful information on a timely basis. Historically, financial reports were prepared on a periodic basis mostly due to time and cost restraints. With advances in computers and accounting software, financial information is now available at intervals less than once a quarter or year. With these advances, real-time accounting as a practice is now economically feasible and necessary to maintain a competitive edge (Rezaee, Ford, \& Elam, 2000). However, at the present time, there is much debate in the field of accounting over the traditional, legacy-batch processing versus the real-time processing system (Mattingly, 2001). As stated by Meigs, et al (1999), all accounting systems execute the following fundamental functions:

1. Interpret and record the effects of business transactions.

2. Classify the effects of similar transactions in a manner that permits determination of the various totals and subtotals useful to management and used in accounting reports.

3. Summarize and communicate the information contained in the system to decision makers. (p. 8)

Batch processing and real-time processing both perform the above functions. What separates and differentiates these types of accounting systems are the speed, accuracy, control, and time in which they report business information. Batch processing collects business transactions then posts them as a group usually on a monthly, quarterly, or even yearly basis. For example, when a check is written, there is a delay before it is posted to the appropriate journals and reports. Real-time processing occurs when a transaction is entered into the system and, subsequently, all journals and reports are instantaneously updated. The transaction impact is immediately reflected on the business accounts. For example, when a check is written it is processed and posted instantaneously and updated to the appropriate reports (Taylor, 2002). Batch processing offers a higher degree of internal control but does not allow on-demand information. Conversely, real-time processing offers fast and current information while lowering the degree of internal control (Mattingly, 2001).

Accounting and information technology are integrated more and more into day-to-day business practices. As such, traditional accounting practices are destined to be replaced in the future by real-time accounting systems (Rezaee, Ford, \& Elam, 2000). According to Mattingly (2001), "many believe that systems which allow continuous measurement and reporting will become the new standard, in sharp contrast to the periodic reporting practices of the legacy, batch—oriented, and modular systems that prevail today" (p. 52). 
Real-time information, furthermore, applies to estimating and budgeting functions. The days of conventional static estimates are numbered. The immediate future calls for dynamic estimates and rolling budgets to be continually updated so that information is accurate and timely (Myers, 2001). This rolling budget applies to the construction industry as well and can be applied specifically to cost variance and job costing. One of the key elements in the 21 st century for a construction firm's successful future is a formal job-control system. The important variables in this system are the estimated cost, actual cost, and percentage of completion in a real-time environment. The construction industry in the immediate future will be operating in real-time. Transactions will be entered and recorded as the work progresses, and reports will be available instantaneously tracking the progress on projects. A system, which incorporates real-time accounting, is essential to track these three key variables and maintain a competitive edge (James, 1999). However, after reviewing the literature and current empirical research, there was minimal descriptive literature concerning the practices of the use of information technology in the accounting functions by home builders. The need for additional studies in this area became visible. The researchers sought to add to the already existing body of knowledge in the fields of accounting and construction management research and potentially benefit Pennsylvania home building contractors.

\section{RESEARCH QUESTIONS}

- $\quad$ Research Question One: To what extent are the differences in the use of accounting or project management software used for the job costing function related to the scale of operations?

- $\quad$ Research Question Two: To what extent are differences in whether or not the primary accounting function is computerized related to the scale of operations?

- $\quad$ Research Question Three: To what extent are differences in the primary program used for the accounting functions by home builders related to the scale of operations?

\section{DATA}

The population of this study consisted of home building firms in the state of Pennsylvania. As to the researchers' knowledge, no single list exclusive to Pennsylvania home building firms existed. Subsequently, the researchers of the study implemented a cluster approach through a multi-stage sampling technique as a means to collect data. In the final phase of the area probability sampling technique, a list of Pennsylvania home building firms, from the sampled counties, was compiled. Responding firms were than classified into three areas: small, medium, and large based on the use three indicator variables: number of employees, home output per year, and annual revenue.

\section{RESULTS}

Research Question One: To what extent are the differences in the use of accounting or project management software used for the job costing function related to the scale of operations?

In order to answer research question one, the survey addressed how often accounting or project management software is used for job costing by home building firms. In order to examine the use of job costing by firm size, one-way analysis of variance (ANOVA) and Tukey multiple comparison tests were utilized. First, the one-way analysis of variance (ANOVA) was performed. Table 1 shows the statistical results of the one-way analysis of variance (ANOVA) for the survey item based on firm size regarding the job costing practice.

Table 1: Computerized Job Costing Practices Examined by Firm Size

\begin{tabular}{lcccccccc}
\hline & & \multicolumn{9}{c}{ Mean } & & \\
\cline { 3 - 5 } \multicolumn{1}{c}{ Computerized job costing } & $\mathrm{n}$ & Small & Medium & Large & Total & $F$ & $p$ \\
\hline $\begin{array}{l}\text { How often is accounting or } \\
\text { project management }\end{array}$ & 362 & 2.34 & 3.08 & 3.76 & 3.06 & 23.253 & $<.001$ \\
$\begin{array}{l}\text { software used for job } \\
\text { costing on projects? }\end{array}$ & & & & & & & & \\
\end{tabular}

Note. Application Scale: 1 = Never; 2 = Seldom; 3 = Sometimes; 4 = Most Times; 5 = Always 
The data reveal that there are significant differences based on firm size and the use of accounting or project management software for job costing by home building firms $(F=23.253 ; \mathrm{p}<.001)$.

Secondly, a post hoc analysis was performed. A Tukey multiple comparison test was utilized to examine differences between the individual firm sizes (small, medium, and large) as illustrated in Table 2. The post hoc results for the use of computerized job costing showed $\mathrm{s}<\mathrm{m}(\mathrm{p}=.001) ; \mathrm{s}<1(\mathrm{p}<.001) ; \mathrm{m}<1(\mathrm{p}=.004)$.

Table 2: Post Hoc Computerized Job Costing Practices Examined Between Firm Size

\begin{tabular}{|c|c|c|c|c|c|c|c|}
\hline \multirow[b]{2}{*}{ Cost codes } & \multirow{2}{*}{$\begin{array}{l}\text { Size } \\
\text { Class }\end{array}$} & \multirow{2}{*}{$\begin{array}{l}\text { Size } \\
\text { Class }\end{array}$} & \multirow{2}{*}{$\begin{array}{l}\text { Mean } \\
\text { Differ. }\end{array}$} & \multirow{2}{*}{$\begin{array}{l}\text { Standard } \\
\text { Error }\end{array}$} & \multirow[b]{2}{*}{ Sig. } & \multicolumn{2}{|c|}{$\begin{array}{c}95 \% \text { Confidence } \\
\text { Level }\end{array}$} \\
\hline & & & & & & Lower & Upper \\
\hline \multirow{6}{*}{$\begin{array}{l}\text { How often is accounting or } \\
\text { project management } \\
\text { software used for job } \\
\text { costing on projects? }\end{array}$} & small & medium & -0.740 & 0.207 & 0.001 & -1.23 & -0.25 \\
\hline & & large & -1.410 & 0.207 & $<.001$ & -1.90 & -0.93 \\
\hline & medium & small & 0.740 & 0.207 & 0.001 & 0.25 & 1.23 \\
\hline & & large & -0.670 & 0.208 & 0.004 & -1.17 & -0.18 \\
\hline & large & small & 1.410 & 0.207 & $<.001$ & 0.93 & 1.90 \\
\hline & & medium & 0.670 & 0.208 & 0.004 & 0.18 & 1.17 \\
\hline
\end{tabular}

Note. Application Scale: 1 = Never; 2 = Seldom; 3 = Sometimes; 4 = Most Times; 5 = Always

Research Question Two: To what extent are differences in whether or not the primary accounting function is computerized related to the scale of operations?

The survey was used to address the second research question by gathering information pertaining to the principal method used in the firms business for accounting. This item measured whether or not the primary accounting function is computerized. Chi-square tests were used to address this fundamental question. Table 3 shows the statistical results of whether or not home builders used a computerized system in their accounting procedures.

Table 3: Computerization of Accounting Functions Examined by Firm Size

\begin{tabular}{lcccccc}
\hline & \multicolumn{6}{c}{ Firm Size } \\
\cline { 2 - 5 } \multicolumn{1}{c}{ Accounting process } & Small & Medium & Large & Total & $x^{2}$ & $p$ \\
\hline Non-Computerized & 35 & 12 & 4 & 51 & & \\
Computerized & 88 & 105 & 115 & 308 & & \\
\hline & 123 & 117 & 119 & 359 & 33.471 & $<.001$ \\
\hline
\end{tabular}

The results of the chi square analysis show that there are significant differences $(\chi 2=33.471 ; p<.001)$ in the use of a computerized accounting function among the three home building firm sizes.

Research Question Three: To what extent are differences in the primary program used for the accounting functions by home builders related to the scale of operations? 
The survey was used to address the third research question by gathering information pertaining to firms using computerized packages to determine the primary program used for their accounting functions and whether differences existed among the companies based on size. The results are shown in Table 4 broken down by accounting software, construction software, and other. Chi-square tests were used to address this question.

Table 4: Computerized Accounting Programs Examined by Firm Size

\begin{tabular}{lcccccc}
\hline & \multicolumn{5}{c}{ Firm Size } & \\
\cline { 2 - 5 } \multicolumn{1}{c}{ Program } & Small & Medium & Large & Total & $x^{2}$ & $p$ \\
\hline Accounting Software & 77 & 86 & 67 & 230 & \\
Construction Software & 3 & 14 & 36 & 53 & \\
Other & 8 & 5 & 12 & 25 & & \\
\hline Total & 88 & 105 & 115 & 308 & 33.076 & $<.001$ \\
\hline
\end{tabular}

The results of the chi square analysis showed that there are significant differences $\left(\chi^{2}=33.076 ; p<.001\right)$ in the primary program used for accounting by home builders when the accounting function is computerized between the three home building firm sizes.

\section{CONCLUSIONS AND RECOMMENDATIONS}

According to the findings, the researchers concluded that there are significant differences among and between firm sizes in the use of accounting and project management software for the job costing function by Pennsylvania home building firms. The largest difference in usage of computerized job costing became visible between large and small firms and between medium and small firms and a less pronounced, but still significant, difference between large and medium firms. Overall, Pennsylvania home building firms are split down the middle in the use of a computerized job costing system to manage projects. Job costing is an important component of successfully managing a construction project and computerizing the process cannot only save time, but also money. The first recommendation is for Pennsylvania home building firms to have an accurate, timely, and dependable system in place to calculate job costs for comparison to budget. Ramos (2002) states that "it is critical that management realizes the importance of periodic comparison of actual costs to budgets (bid costs)" (p. 102). In the Pennsylvania home building industry, smaller firms have to become more computerized in the job costing area if they are going to compete in an increasingly global environment in the future.

Secondly, the data supported the hypothesis that significant differences existed among firm sizes between the use of a computerized accounting system or manual accounting system. The second recommendation is for home builders who are not computerized to benefit by implementing commercial accounting software which will help increase performance in their construction practices. The results of this study show that many firms still do not use information technology to perform even basic tasks, even though accounting software is available at affordable rates. These findings concur with the results of a 2004 study on home builders in which Hutchings and Christofferson (2004) found that even the most primitive accounting tasks were completed manually.

The final area of the study concentrated on what type of accounting program was employed in firms that have a computerized accounting system. The data revealed that there are significant differences among firm sizes in the primary program used for accounting when a firm is computerized. The data support the notion that larger firms are more computerized and have the tendency to use construction specific accounting software more than medium and small firms. However, large firms still predominantly use commercial accounting packages in favor of construction specific accounting software by a 2 to 1 margin. Based on the results of this study, over $75 \%$ of firms that are computerized use commercial accounting packages with Quick Books being the number one package in use by all three sizes of firms. The final recommendation is for small and medium size firms to take a look at the 
benefits available to them in regard to commercially available accounting software and take advantage of the scale of economies that were once limited to larger firms.

\section{AUTHOR INFORMATION}

Dr. Mark Law is an Associate Professor of Accounting at Bloomsburg University of Pennsylvania. He received his $\mathrm{Ph} . \mathrm{D}$. from the Pennsylvania State University and is a licensed Certified Public Accountant. His career began in public accounting as a staff accountant before he established and developed an accounting and computer consulting practice prior to moving into academia. His research interests include the areas of accounting information systems, construction technology, and emotional intelligence.

Dr. Nancy Coulmas is a Professor of Accounting at Bloomsburg University of Pennsylvania. She received her PhD in Accounting from the Pennsylvania State University. She worked for several years as a Cost Accountant for a private company, before pursuing an MBA and a PhD. Her research interests include the areas of cost and managerial accounting and accounting information systems.

\section{REFERENCES}

1. Al-Jibouri, S. H. \& Mawdesley, M. J. (2002). A knowledge based system for linking information to support decision making in construction. Electronic Journal of Information Technology in Construction. 7, 83-100. Retrieved June 14, 2003, from http://www.itcon.org/2002/6

2. Forehand, W. B. (2002). Cost-shifting-The hidden risk of construction accounting. Journal of Construction Accounting \& Taxation, 12(6), 15-18.

3. Hutchings, D. M. \& Christofferson, J. P. (2004). Management practices of residential construction companies producing 25 or fewer units annually. International Journal of Construction Education and Research, 9(2), 34-44.

4. James, R. E. (1999). Twelve foundation blocks for the new millennium. Retrieved February 1, 2004 from, http://www.fminet.com/sc.asp?t=3\&s=18\&p=180\&at=6

5. Kartam, N. A. \& Kartam, S. A. (2001). Risk and its management in the Kuwaiti construction industry: A contractors' perspective. International Journal of Project Management, 19(6), 325-335.

6. $\quad$ Mattingly, T. (2001). How to select accounting software. The CPA Journal, 71(11), 48-53.

7. Meigs, R. F., Williams, J. R., Haka, S. F., \& Bettner, M. S. (1999). Accounting: The basics for business decisions (11th ed.). New York: Irwin McGraw-Hill.

8. $\quad$ Myers, R. (2001). Budgets on a roll. Journal of Accountancy, 192(6), 41-46.

9. Partnership for Advancing Technology in Housing. (2001). Information technology to accelerate and streamline home building. (NAHB Research Center). Upper Marlboro, MD.

10. Ramos, M. J. (2002). A CPA's guide to accounting, auditing, and tax for construction contractors 2 nd ed. New York: American institute of certified public accountants, Inc.

11. Rezaee, Z., Ford, W., \& Elam, R. (2000, Apr.). Real-Time accounting systems. The Internal Auditor, 57(2). p. 62-67.

12. Taylor, J. J. (2002). The real time world: Using online budget and financial applications at higher education institutions. Dissertation Abstracts International, 63 (03), (UMI No. 3045537)

13. User's guide volume II: General ledger, payroll, job cost, fixed assets [Computer software and manual] (2002). Norcross, GA: Peachtree Software, Inc.

14. Wiersema, W. H. (1996). Upgrading your job costing: How to track costs and take the first step toward improved efficiency. Electrical Apparatus, 49(9), 42-43. 